\title{
Summary of Operation and Maintenance with BIM Technology for Large Commercial Complex Architecture
}

\author{
$\mathrm{De} \mathrm{Xu}$ \\ Jiangsu Open University College of Civil Engineering \\ Nanjing, China
}

\begin{abstract}
In recent years, BIM operation and maintenance has begun to be applied in a commercial complex architecture, but BIM research and application in operation and maintenance stage is still in its infancy at home and abroad. This paper reviews the current status of research and application of BIM in operation and maintenance in domestic and overseas, mainly introducing the key technologies and related system development status, and inducing the various operation and maintenance functions and project applications that have been realized. On the basis of summarizing the current situation, the existing challenges and bottlenecks in this field are proposed, and the future development direction of BIM operation and maintenance has prospected.
\end{abstract}

Keywords-BIM operation and maintenance, commercial complex, review

\section{ApPlicAtion OF BIM teChNOLOGY}

\section{A. Application of foreign BIM technology}

BIM (Building Information Modeling) originated in the United States at the earliest, commonly known as the building information model in China. Based on 3D digital imaging technology and a common standard (commonly used IFC, Industry Foundation Class), BIM integrates a variety of modeling tools to simulate the real information of the building with digital information, thus obtaining the relevant data of various engineering information of the construction project to become a three-dimensional modeling system with a large amount of building entity information, also a collection of information throughout the life cycle of a project[1]. The research object of BIM Technology is the building entity. In essence, it is the product of information development and information management technology used in project management[2].

In 2009, Wisconsin became the first state government to require the use of BIM for new large public building projects in the state. The Texas Facility Council also announced the requirement to apply BIM technology for design and construction projects invested by the state government.

In 2010, the Ohio State Government issued the BIM agreement, and Japan's Ministry of land and transportation announced the implementation of BIM Technology. At present, the application of BIM in Japan has been extended to the whole country and has been promoted by the government. There are many government agencies in Europe and South
Korea that are committed to the development of BIM application standards. There are many government agencies in Europe and South Korea that are committed to the development of BIM application standards. BIM is leading to an unprecedented revolution in the cause of the collective "movement" of architecture.

\section{B. Application of domestic BIM technology}

The engineering construction industry of China has introduced BIM technology since 2003. The current application is mainly based on design companies. Various BIM consulting companies, training institutions, government and industry associations have begun to pay more attention to the application value and significance of BIM. At present, Chinese scholars have done a lot of work on the basic theory and practical application of BIM.

In terms of basic theory, Zhang Jianping et al. developed an intelligent property management system[3]. The system comprehensively applies the international industrial standards of the construction industry, and establishes a standard-based building property information model and data exchange interface, which realizes information exchange and sharing in the construction property management stage, design stage and construction stage; in the field of design, BIM technology has been applied to a large number of engineering practices to accurately check for collisions between structural members. In terms of construction, people use BIM technology to carry out risk management and dynamic simulation of the construction process to prevent engineering rework caused by human factors and save engineering funds; in the development and utilization of urban underground space, the existing research mainly focuses on the application of BIM technology in urban underground transportation. Wang Huizhen et al. studied the application of BIM in underground construction engineering by taking the construction of the subway station as an example[4]. $\mathrm{Yu}$ Jinyong et al. Introduced the application of BIM Technology in subway installation engineering based on the Construction of Shilong Road Station of Shanghai Rail Transit Line 11 phase II[5]. Zhang Chengfang et al. briefly analyzed the application of BIM technology in subway construction safety[6]. Zeng Dalin et al. discussed the application of BIM in the underground engineering of the front square of Jinan West Railway Station[7]. Gao Yonggang et al. studied the construction of BIM technology in Hangzhou East Railway Station and Yinchuan Railway Station[8]. 


\section{DifFiCUlties AND PROBLEMS IN THE FORMULATION OF BIM STANDARDS IN CHINA}

\section{A. The practice application experience is shallow and standard nature is not differentiated}

The construction industry informatization construction has developed rapidly in China since 2011. The state and relevant government departments have also issued articles continuously, emphasizing the acceleration of the standardization process and the preparation of information standards. However, BIM technology has not been widely promoted and applied worldwide. For the field of building systems, this is different from other existing material technology, not fully mature new technology. So far, there are only a few cases of applying BIM technology to the whole life cycle of actual construction projects in China, which shows that BIM technology is not mature enough. However, the BIM standard should be developed gradually based on the mature practical experience. At present, the National BIM Standard is based on the foreign standard, and it is not clear whether the existing BIM Standard is mandatory. Regardless of the mandatory standards or the recommended standards, it has a major impact on the development of the entire industry. In the process of standard preparation, only in accordance with their own development of the specific circumstances and rich practical experience can determine the nature of the standard, so as to ensure the maximum benefit of the entire industry.

\section{B. Multi-level standard system has not yet been formed}

According to statistics, as of mid-November 2015, the BIM Development Alliance has issued nearly 20 information exchange technology standards for various professions in China by the middle of November 2015. There are countless BIM standards issued by the state and local governments, but the multi-level standard system has not been formed[9]. In the "Standardization Law of the People's Republic of China", the implementation of enterprise standards is guided by national standards, industry standards and local standards. The BIM standard system should cover these four levels in China, forming a system framework system that is interconnected and integrated without losing the hierarchy. It can be seen from the figure that only national, industry, and local standards cannot adapt to the development of BIM standards. The formulation of national, local, and industry standards are ultimately used to guide corporate standards. The landing of the BIM standard ultimately depends on the enterprise standard, and must be shifted from the standard application level to the implementation level. In China, some large-scale design institutes and construction units have started to prepare BIM enterprise standards, but many enterprises have not been able to prepare standards based on their understanding of BIM, just to better show the visual effect of BIM for construction projects, resulting in confusion in information exchange, unclear parameter classification and other problems still exist in most BIM standard cases. Therefore, before developing BIM standards, it is important to understand the building information model. In addition, the BIM standard should be a model creation standard for the entire life cycle of a building project, including the whole process of design, construction, and operation.

\section{BIM OPERATION AND MAINTENANCE SYSTEM FUNCTION}

The BIM building operation and maintenance platform consists of building model, building facility information database, building automation system and property management system[10-11]. All modules are displayed and used based on BMI stereo model interface. The important functions are as follows.

(1) Space management: Intuitive three-dimensional commercial building space perspective and office workstation layout display can enable the logistics to fully grasp the use of commercial complex building space, rationally allocating commercial functional space to eliminate space waste for maximum utilization of space resources, which can meet the spatial adjustment and expansion of various commercial stores.

(2) Equipment management: The position of the water and electric heating equipment and the concealed pipeline of the building in the BIM model are clear at a glance. The elevator system, fire protection system, and video surveillance system can also be dynamically displayed. As all facilities can be browsed by disciplines, the system view interface displayed by the method is simple and clear, making that the maintenance personnel are very clear about the location of the equipment, which can achieve rapid and accurate equipment positioning. BIM carries a wealth of equipment account information, which can be called at any time, such as equipment instruction, production date, manufacturer, service life, etc., without looking for the original drawings, contracts and other data of paper media. The maintenance plan can be formulated in the system. It will automatically remind the startup equipment maintenance process, and can also make fault pre-judgment, in favor of reducing the number of equipment failures to improve maintenance efficiency and save maintenance costs.

(3) Building intelligent monitoring: Comprehensive monitoring of equipment in buildings through software, including building automation systems (BAs), fire protection systems, video surveillance systems (CCTV), underground parking systems, access control systems, etc., to realize the real-time monitoring and early warning of the operation status of building air conditioning, water supply and drainage, power supply, fire protection and other equipment. The security system can use the BIM three-dimensional space simulation to adjust the surveillance camera surveillance area and the layout, for the purpose of preventing the monitoring of dead angles.

(4) Energy management: The commercial complex is a large energy consumer. The energy consumption data collected by various sensors and smart meters can be connected to the BIM model to realize energy dynamic monitoring. The recorded historical data can be used as the basis for energy consumption analysis comparison, thereby optimizing the abnormal energy consumption.

(5) Emergency drill: Using the stereoscopic and intuitive features of the BIM model, it is possible to conduct training for commercial complex disaster escape drills, such as evacuating command personnel after a disaster, providing location information and optimal escape routes for trapped personnel to reduce personnel and financial losses caused by disasters. 
(6) Asset management: The management of the assets and facilities of the commercial complex has been in a state of confusion, with large discrepancies between accounting cards and physical objects. However, in BIM model, fixed assets in commercial complex buildings can be managed visually based on location. The layout of fixed assets in floors and rooms can be displayed from multiple angles, and information such as service life, manufacturer can also be consulted in real time. Through RFID tag to identify asset status, it can also realize automatic management and no longer rely on paper account. By identifying asset status through RFID tags, automated management can be implemented and no longer relies on paper ledgers.

\section{PRoblems Existing In the TeChNOLOGY APPLICATION OF BIM IN THE LARGE COMMERCIAL COMPLEX}

The logistics equipment of the commercial complex is scattered, with high management requirements and difficult management. The digital, visual and intelligent level of later operation and maintenance of facilities and equipment is low, so it is impossible to combine spatial data with an early warning for possible operation events of equipment and facilities. The equipment construction of the commercial complex is out of line with the operation and maintenance in the later period, which results in more human, material and financial resources to be invested in the operation and maintenance of the equipment in the later period.

\section{BIM OpERATION AND MAINTENANCE TECHNOLOGY LEVEL}

\section{A. Technical route}

(1) In view of similar systems and their development trend domestic and foreign, the overall function of the positioning system is based on the system integration of BIM+FM. Similar systems at home and abroad and their development trends are summarized, aiming at creating international advanced features and the overall function of the positioning system.

(2) The electrical system is selected as a typical system function, taking the application as the guidance to carry on the detailed function design according to this research concrete situation and the request. The electrical system is chosen as a typical functional application for technical breakthroughs and practical applications. Detailed functions of BIM-based visual operation are designed, and key technology research is carried out on this basis.

(3) Progress and breakthrough in key technology research. The docking of BIM and FM is a new technological breakthrough. The subject focuses on the visual operation and maintenance of the electrical system, and studies the corresponding key technologies, including the transformation of the BIM construction model to the operation and maintenance model, the lightweight of the BIM model, and the reading of heterogeneous data, integration and integration, three-dimensional visualization of operation and maintenance data, visual early warning of operation and maintenance data and other key technologies.
(4) Operational test of the prototype system. For the developed prototype system, the vertical forest subproject is selected for test application to test the function, efficiency, stability, operability, friendliness and agility of the system. Aiming at the problems encountered in the test, optimization, adjustment and improvement are carried out.

(5) According to the experimental application of the electrical system, the functional design and key technologies of the extended operation system are formulated. The functional design and realization method of the comprehensive docking between BIM and the operation and maintenance system is developed, as well as the key technologies that may be encountered and not solved.

\section{B. Difficulties in BIM Operation and Maintenance}

(1) BIM represents a new building construction and management mode. The operation and maintenance of commercial complex buildings based on BIM is rarely applied, and there is a little experience to learn from, which needs to be explored and summarized constantly.

(2) The initial implementation cost of adopting BIM technology is relatively high, and the benefits and costs have not been extensively evaluated and tested by the market.

(3) The operation and maintenance management mode of BIM is a new support technology for commercial complexes, with a large cognitive span and a long adaptive process.

(4) The implementation of BIM operation and maintenance requires the organizational structure of the logistics support department of the commercial complex to be changed accordingly. The adjustment of departments involves the system of public institutions, and the improvement of personnel information skills is also a slow process.

\section{PROBlems SOLVED BY BIM OPERATION AND MAINTENANCE TECHNOLOGY IN LARGE COMMERCIAL COMPLEXES}

\section{A. Solving the "visualization" problem of logistics operation and maintenance of large commercial complexes}

The spatial layout of modern commercial complexes has become more diversified and the equipment has been more complicated. Although the traditional charting methods and text description methods can reflect the operation status and early warning status of facilities and equipment to some extent. However, there are defects in the positioning of the signal source, which cannot directly reflect the spatial position. This research topic can solve the key technical problems in the "visualization" of the logistics operation and maintenance of large commercial complexes.

\section{B. "Value-added" to achieve commercial complex facilities operations}

This research topic integrates the building information model data with the real-time data of equipment operation to study the data analysis technology of facility equipment operation and maintenance energy consumption. Benchmark's solution is established to optimize operation and maintenance strategy. Abnormal operation and maintenance are predicted and warned, and value-added services are provided for the 


\section{ACKNOWLEDGMENT}

sustainability of facility operation. It can effectively solve the practical problems of the current commercial complex logistics equipment dispersion, high management requirements, and poor management team structure.

\section{Effective realization of Life Cycle Management of Commercial Complex Construction and Operation}

The disconnection between construction and operation and maintenance is a prominent practical problem of public construction projects. This project realizes the transmission of BIM to the operation and maintenance phase during the construction phase by modeling the BIM data modeling method in the construction phase. And through the interface between BIM and the existing operation and maintenance platform, data sharing, integration and integration are achieved, which provides a technical basis for the life cycle management of commercial complex projects.

\section{CONCLUSION}

BIM is an information revolution in the construction sector that has changed the way the construction industry is produced and managed. With the continuous diversification and modernization of large-scale commercial complex buildings, as well as the technical requirements for construction and operation management, are constantly improving, all-digital design, construction and operation and maintenance management need to be realized by means of BIM. The operation and maintenance phase is the most important stage of the entire building life cycle. Based on the above review and discussion, it can be considered that the BIM application in the operation and maintenance phase is still in the initial stage of research, facing many challenges and bottlenecks. Despite this, its potential for further development and promotion is enormous. As the second information revolution in the construction field, BIM technology will play a greater role in operation and maintenance management.
This study is financially supported by the Jiangsu Construction System Science and Technology Project, Project No. 2018ZD136

\section{REFERENCES}

[1] Chen Guangjun, Zhang Huijun, Lv Bingbing, Sun Shaonan, Application Research of BIM technology in project operation stage, Taihong Construction and Development Co., Ltd., North China University of Water Conservancy and Electric Power, Journal of Zhongzhou University, April 2016.

[2] Hu Zhenzhong, Peng Yang, Tian Peilong, Review of research and application of operation and maintenance management based on BIM, Department of Civil Engineering, Tsinghua University, Journal of Graphics, October 2015.

[3] Zhang Jianping, Liang Xiong, Liu Qiang, Wang Xiuchang, Wang Yangli, BIM-based project management system and its application [J]. Information Technology of Civil Engineering, pp.1-6, April 2012.

[4] Wang Huizhen, Li Yanfeng, Zhao Xuefeng, Zhang Jin., Application Research of BIM Technology in Underground Building Construction-Taking Metro Station as an Example [J]. China Science and Technology Information, pp.72-73, May 2013.

[5] Yu Jinyong, Lin Min, Application of BIM technology in subway installation engineering $[\mathrm{J}]$. Information Technology of Civil Engineering, pp.86-91, May 2013.

[6] Zhang Chengfang, Li Chao. Analysis of the application of BIM technology in subway construction safety [J]. Henan Science and Technology, pp.130-131, September 2013.

[7] Zeng Dalin, Zhao Lingmin, Yue Guangfei. BIM application of underground engineering in front square of Jinke West Railway Station [J]. Information Technology of Civil Engineering, pp. 71-77, April 2012.

[8] Gao Yonggang, Li Guangjin, Based on the application of BIM visualization technology in Hangzhou East Railway Station [J]. Civil and Architectural Engineering Information Technology, pp.55-58, February 2010.

[9] Pan Ting, Wang Wei, Summary of BIM standards research at home and abroad, School of Civil Engineering, Nanjing University of Technology, Journal of Engineering Management, pp.1, March 2017.

[10] Li Qian, Xu Gaoqiang, Wei Haimin, Research on the management system of comprehensive pipe gallery based on BIM, School of Management, Xi'an University of Architecture and Technology, Journal of Underground Space and Engineering, February 2018.

[11] Mao Xin, Application of BIM in hospital building operation and maintenance management, Beijing Maternity Hospital Information Center, Capital Medical University, April 2016. 